\section{Granulation, toxische}

H. Baum

Institut für Laboratoriumsmedizin, Mikrobiologie und Blutdepot, Regionale Kliniken Holding RKH GmbH, Ludwigsburg, Deutschland

Englischer Begriff toxic granulation

Definition Vergröberte dunkelbläulich bis bräunliche Granulation der neutrophilen Granulozyten.

Beschreibung Die toxische Granulation (s. Abbildung) beruht auf einer Persistenz der azurophilen Granulation der Promyelozyten ( $\triangleright$ Promyelozyt) bei überstürzter Nachbildung bzw. beschleunigter Ausschüttung der neutrophilen Granulozyten ( $\triangleright$ Granulozyten, segmentkernige und $>$ Granulozyten, stabkernige).

Die Abbildung zeigt die toxische Granulation bei einem neutrophilen Granulozyten (Pfeil); zum Vergleich ein normaler neutrophiler Granulozyt (1000×, May-Grünwald-Giemsa-Färbung):

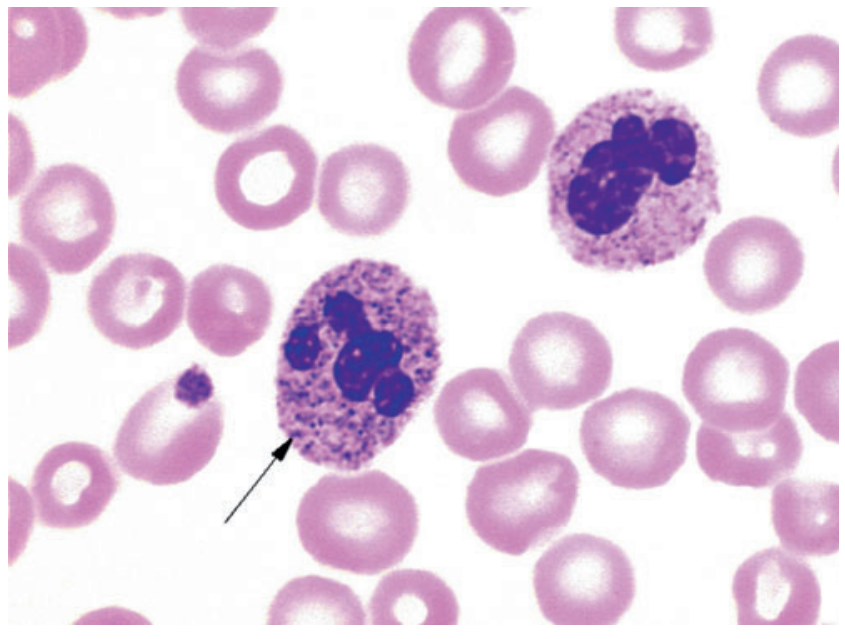

Ursächlich für das Auftreten einer toxischen Granulierung sind infektiöse oder toxische Prozesse, aber auch die therapeutische Gabe granulozytärer Wachstumsfaktoren ( $>\mathrm{G}$ CSF, $>$ GM-CSF) gehen mit dem Nachweis einer toxischen Granulation der neutrophilen Granulozyten einher.

\section{Literatur}

Koeppen KM, Heller S (1991) Differentialblutbild. In: Boll I, Heller S (Hrsg) Praktische Blutzelldiagnostik. Springer, Berlin/Heidelberg/ New York, S 179 